\title{
Şo(f)woblycborner Şerr,
}

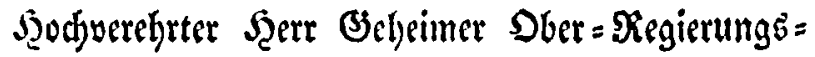
Ratly und Ritter!

\begin{abstract}
Durdidrungen von der Heberzscugung, daf die Bildung im evangelif(d)=djriftlidjen Ġlauben die leitende Joce bes erbabenen von fo grof́en Erfolgen begleitcten 2 Birfenz

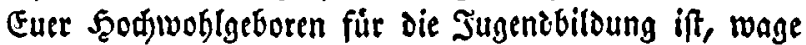

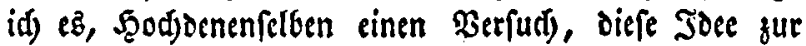
weiteren und beftimuteren 2 nnerfennung gu bringen, nit

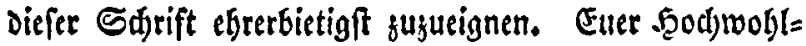
seboren fann id) Diefelbe gmar nur mit der $\mathfrak{B i t t e}$ um

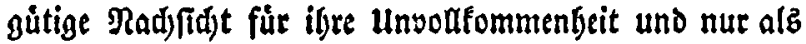

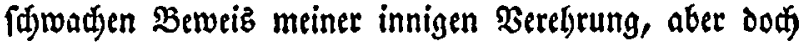
mit dem Serwuftefein úberteidfen, die WBabrbeit mit al=

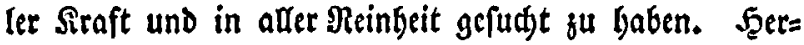
vorgegangen aus einem Derbáltniffe, weldję meine wif=

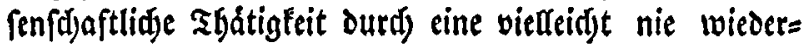

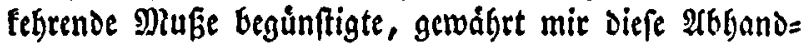

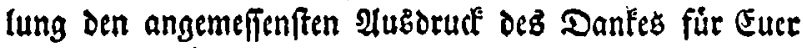

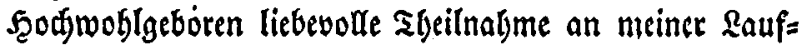
bagn, weldye mir mit biefer 9luke die saeit zu ijger

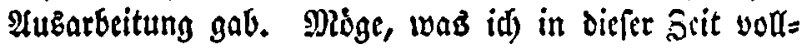

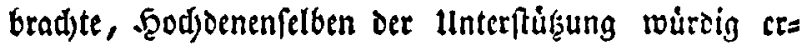
(đ̦einen, beren id) mid) erfreute, und móge $\mathfrak{c b}$, wie un=
\end{abstract}


volfommen aud im Eingelnen, ood im 2 ffgemeinen zur immer glưdélidern Qjofung ber biddfen. Aufgabe als Ier Ergiebung Geitragen: Den jugendlidjen Geift auf bas Eine Rotbwendige linzurid)ten. Mloge der $\mathfrak{A}$ (ágủtige diefen wie jeden andern şweig der Jugendbildung fei= ner $\mathfrak{B o l e n d u n g}$ immer náber fübren, und (Euer $\mathfrak{b}$ od)= wohlgeboren nod) lange in auşgebreiteter und fegenżrei= d)er $\mathfrak{W}$ sirffamfeit Dafür crbalten.

Mit tiefer Berelgrung und DanfGarfeit

Euer Şodjwohlgetoren
Brieg
gethurfamifter
am fweiten Dftertage
1828.
2. Dobertag. 